https://doi.org/10.34179/revisem.v6i1.14760

\title{
UMA PROPOSTA PEDAGÓGICA PARA O DESENVOLVIMENTO DAS COMPETÊNCIAS ESTATÍSTICAS POR MEIO DE PESQUISA NA COMUNIDADE
}

\section{A PEDAGOGICAL PROPOSAL FOR DEVELOPMENT OF STATISTICAL SKILLS THROUGH COMMUNITY RESEARCH}

\author{
Diogo Israel Schwanck \\ Universidade Federal do Rio Grande do Sul - UFRGS \\ dischwanck@gmail.com \\ Luciana Neves Nunes \\ Universidade Federal do Rio Grande do Sul - UFRGS \\ lununes@,mat.ufrgs.br
}

\section{Resumo}

Com o objetivo de identificar elementos potenciais para o desenvolvimento de uma pesquisa estatística, em comunhão aos preceitos da Modelagem Matemática, no contexto em que uma escola está inserida, este trabalho apresenta uma proposta para o ensino de Estatística no Ensino Fundamental por meio de uma pesquisa estatística envolvendo a comunidade na qual a escola localiza-se. Os estudantes participantes eram de uma turma de terceiro ano do terceiro ciclo (equivalente ao nono ano do Ensino Fundamental) de uma escola pública municipal de Porto Alegre/RS, a partir do tema gerador "as residências da região do Parque dos Maias". A análise dos dados foi realizada através da identificação dos eventos críticos, por meio da captura de dados audiovisuais. Destacaram-se como elementos potenciais a mediação adequada ao longo do processo experienciado, o ambiente propício à autonomia e autoria do estudante, a valorização do trabalho e o desenvolvimento de espaço colaborativo de trabalho. O desenvolvimento deste trabalho possibilitou aos estudantes uma reflexão crítica sobre seus questionamentos relacionados aos aspectos socioculturais, competência essa fundamental para o pleno desenvolvimento da cidadania.

Palavras-chave: Educação Estatística. Modelagem Matemática. Educação Matemática Crítica. Educação Estatística Crítica. Pesquisa Estatística

\begin{abstract}
In order to identify potential elements for the development of statistical research, in line with the precepts of Mathematical Modeling, in the context in which a school is inserted, this work presents a proposal for the teaching of Statistics in Elementary Education through a research statistics involving the community in which the school is located. The participating students were from a third year class of the third cycle (equivalent to the ninth year of elementary school) from a municipal public school in Porto Alegre / RS, based on the generator theme "the residences in the Parque dos Maias region". Data analysis was performed by identifying critical events, by capturing audiovisual data. The potential elements that stood out were the appropriate mediation throughout the process experienced, the environment conducive to the student's autonomy and authorship, the
\end{abstract}


valorization of work and the development of a collaborative work space. The development of this work enabled students to reflect critically on their questions related to socio-cultural aspects, a competence that is fundamental for the full development of citizenship.

Keywords: Statistical Education. Mathematical Modelling. Critical Mathematics Education. Critical Statistics Education. Statistical Research

\section{INTRODUÇÃO}

O ensino de Estatística tornou-se foco de pesquisa no Brasil nas duas últimas décadas (SANTOS, 2015) por, entre diversos motivos, ser elemento constante nos documentos oficiais relativos aos parâmetros curriculares brasileiros. Mais recentemente, a Base Nacional Comum Curricular (BNCC) (BRASIL, 2017) indicou a necessidade do desenvolvimento de conceitos relacionados ao tratamento da informação e da incerteza desde os primeiros anos da escolarização. A Probabilidade e Estatística aparece em destaque, na forma de uma das cinco unidades temáticas que compõe a estrutura de organização do componente curricular Matemática. Salienta-se desse documento a expectativa almejada para os estudantes concluintes do Ensino Fundamental:

[...] que os alunos saibam planejar e construir relatórios de pesquisas estatísticas descritivas, incluindo medidas de tendência central e construção de tabelas e diversos tipos de gráfico. Esse planejamento inclui a definição de questões relevantes e da população a ser pesquisada, a decisão sobre a necessidade ou não de usar amostra e, quando for o caso, a seleção de seus elementos por meio de uma adequada técnica de amostragem. (BRASIL, 2017, p.231).

Borba et al. (2011) ressaltam que, mesmo com as recomendações relativas ao desenvolvimento das habilidades relativas à Estatística na Educação Básica, o referido trabalho ainda é incipiente, quando comparado com as demais áreas expressas nos documentos oficiais - Aritmética, Álgebra, Geometria e Grandezas e Medidas.

Concomitante a referida edição de documentos norteadores da composição do currículo escolar, o surgimento do movimento da Educação Estatística propôs-se a questionar o conhecimento de normas e procedimentos estatísticos por meio da construção de competências relacionadas entre si, de forma a desenvolver a capacidade de questionamento e interpretação do contexto, voltadas para a formação de uma cidadania crítica, consoante aos ideais da Educação Crítica, fundamentadas nas obras de Paulo Freire e Henry Giroux.

Visto isso, o presente trabalho explora a congregação dos ideais da Educação Crítica, por meio da metodologia de Modelagem Matemática em sua perspectiva sócio- 
crítica, em uma experiência desenvolvida com estudantes de uma turma de nono ano do Ensino Fundamental em uma Escola Municipal de Porto Alegre, com vista à identificação de elementos potenciais para o desenvolvimento de uma de pesquisa estatística acerca da comunidade na qual escola está inserida, sendo os elementos potenciais a mediação adequada ao longo do processo experienciado, o ambiente propício à autonomia e autoria do estudante, a valorização do trabalho e o desenvolvimento de espaço colaborativo de trabalho. Destacamos que este trabalho se trata de um recorte da pesquisa de mestrado de Schwanck (2019).

\section{COMPETÊNCIAS ESTATÍSTICAS}

A comparação quanto aos conceitos relacionados à Estatística e aos relacionados à Matemática é frequente. Entretanto, há necessidade de que mantenhamos a diferenciação entre as referidas áreas, tendo em vista que, enquanto a Matemática possui caráter determinístico, não podemos inferir à Estatística essa mesma propriedade. Moore (2004) nos afirma que, apesar das semelhanças, a Educação Matemática está para a Educação Estatística assim como a Matemática está para a Estatística: a segunda não é uma subárea da primeira; não as considerando desta maneira, limita-se a Estatística ao estudo da Probabilidade. Por isso, é necessário analisar aspectos relevantes à Educação Estatística que não se fazem necessários à Educação Matemática.

Batanero (2001) observa que "é preciso experimentar e avaliar métodos de ensino adaptados à natureza específica da Estatística, pois a ela nem sempre se podem transferir os princípios gerais do ensino da Matemática” (p. 6). Ao encontro desse pensamento, Campos (2007) explana que os conteúdos e valores desenvolvidos pela Estatística se diferenciam dos desenvolvidos pela Matemática, apesar de fazer uso de conceitos matemáticos atuando como coadjuvantes. Isso se dá pelo fato da Estatística ser permeada pelos princípios da aleatoriedade e da incerteza, que fogem ao escopo matemático. Além disso, a existência de elementos subjetivos, como a possibilidade de escolha da organização e apresentação dos dados, sua interpretação, reflexão, análise e tomada de decisões, que emergem como protagonistas dentre os objetivos da disciplina, distinguem o foco da Estatística em relação à Matemática. Ressaltando as palavras de Campos (2007), perceber essa diferenciação: 
[...] leva a uma tomada de consciência sobre os aspectos peculiares à Estatística, que se apresenta como uma ciência em franca evolução, que experimenta mudanças progressivas tanto do ponto de vista de seu conteúdo como de suas demandas de formação. (p. 48)

Nessa perspectiva, diversos autores divulgaram estudos que indicam que o planejamento da formação estatística de um sujeito deve seguir rumo ao desenvolvimento de três grandes competências, sem as quais não seria possível aprender conceitos estatísticos: letramento estatístico, raciocínio estatístico e pensamento estatístico. Visto o recorte realizado para apresentação no presente trabalho, nos ocuparemos de explanar o delineamento das competências de letramento estatístico e pensamento estatístico, estando convidado o leitor para a apreciação da discussão completa do presente estudo em Schwanck (2019).

\section{Letramento estatístico}

O termo letramento está diretamente relacionado à habilidade de ler, compreender, interpretar, analisar e avaliar diferentes gêneros ou tipos textuais, tendo em vista as diferentes práticas sociais desempenhadas pelo sujeito (SOARES, 2014). Quando esse conceito é trazido para a Educação Estatística, há diferentes leituras a seu respeito, mas elas convergem para a ideia de comunicação estatística, compreendendo, desta forma, a leitura, a escrita, a demonstração e a troca de informações de diferentes elementos estatísticos (tabelas, gráficos, medidas-resumo), em uma perspectiva crítica sobre tais informações.

Gal (2002) define letramento estatístico como a habilidade de um indivíduo interpretar, avaliar criticamente e comunicar informações estatísticas. Além disso, em (GAL, 2004), há a ênfase de que tal competência se refere a dois componentes interrelacionados: a habilidade de interpretar e avaliar criticamente as informações estatísticas, os argumentos relacionados com os dados de pesquisa e os fenômenos estocásticos que podem ser encontrados em diferentes contextos e a habilidade para discutir ou comunicar suas reações a essas informações estatísticas, tais como suas interpretações, suas opiniões e seus entendimentos sobre o seu significado.

Tais habilidades não devem ser vistas de forma isolada, pois estão correlacionadas com uma série de conhecimentos estatísticos e com atitudes que devem ser desenvolvidas 
e valorizadas nos estudantes. Nessa perspectiva, Campos, Wodewotzki e Jacobini (2013) reforçam as premissas de Gal (2002), afirmando que, além dos conhecimentos matemáticos e estatísticos, o estudante necessita ter entendimento do contexto do problema. Além disso, são necessários elementos adicionais para avaliação crítica da informação, como ter a atitude de fazer questionamentos, agindo ativamente sobre os dados e resultados obtidos.

Garfield e Gal (1999) explicam que o uso da linguagem estatística é o aspecto que deverá ser destacado no desenvolvimento do letramento estatístico. Cabe destacar que, no que diz respeito à linguagem estatística, estamos elencando aspectos como o uso de terminologia, símbolos e termos, a habilidade de interpretar gráficos e tabelas e de compreender informações estatísticas em diferentes mídias.

Em resumo e convergindo os aspectos citados até o presente momento, Rumsey (2002) expõe que:

Primeiro, nós queremos que nossos alunos se tornem bons 'cidadãos estatísticos', entendendo estatística o suficiente para ser capaz de consumir as informações com as quais somos inundados diariamente, pensando criticamente sobre essas informações e tomando boas decisões com base nelas. Alguns pesquisadores chamam isso de letramento estatístico. (p.1)

Porém, não é suficiente que o sujeito se limite ao uso de sua criticidade, mas, também, explore a relação dos dados e modelos existentes às situações reais do contexto, o que nos é explicado pelo pensamento estatístico, apresentado a seguir.

\section{Pensamento estatístico}

Snee (1999) indica que a pesquisa, a prática e a educação estatística entraram em uma nova era, afinal, o foco passou a ser o desenvolvimento do pensamento estatístico. Isso só foi possível graças ao desenvolvimento de recursos tecnológicos que possibilitaram aos estudantes que os cálculos fiquem em segundo plano, dando espaço para a compreensão dos processos e melhor interpretação dos resultados (CAMPOS, 2007).

Mallows (1998) apresenta o pensamento estatístico como a capacidade de relacionar dados estatísticos com situações reais, considerando a existência da incerteza e da variabilidade, buscando novos conhecimentos a partir dos dados conhecidos. Assim, o pensamento estatístico ocorre ao associar um modelo matemático à natureza do problema em questão, sendo esse pertinente ao contexto do sujeito. Corroborando essa noção da necessidade do trabalho com situações cotidianas, Campos (2007) afirma que "[...]o 
entendimento dos padrões e estratégias de pensamento usados pelos estatísticos e suas integrações para solucionar problemas reais é fundamental para desenvolver o pensamento estatístico nos estudantes.” (p. 53).

Tendo em vista tais componentes do pensamento estatístico, o desafio passa a ser o desenvolvimento deles junto aos estudantes. Nessa perspectiva, Campos, Wodewotzki e Jacobini (2013) explicam que:

\begin{abstract}
Apesar de não ser possível ensiná-los diretamente aos alunos, acreditamos na viabilidade de trabalhar na valorização dos hábitos mentais que permitem aos não estatísticos apreciar melhor o papel e a relevância desse tipo de pensamento, provendo experiências que valorizem e reforcem os tipos de estratégias que desejamos que eles empreguem no tratamento de novos problemas. (p. 39)
\end{abstract}

Dessa forma, é necessária uma proposta de trabalho que se proponha a desenvolver alguns hábitos mentais e habilidades de resolução de problemas necessárias para o pensamento estatístico. Nessa perspectiva, Chance (2002) destaca como essencial a consideração sobre como melhor obter dados significativos e relevantes para responder à questão que se tem em mãos, a reflexão constante sobre as variáveis envolvidas e a curiosidade por maneiras diferentes de examinar os dados levando para a interpretação das conclusões em termos não estatísticos e a preocupação com o pensar além do livro-texto.

Campos (2007) contribui com a discussão, ao indicar a necessidade de que os dados a serem trabalhados pelos estudantes possuam algum significado contextualizado com a realidade, além de evidenciar a necessidade de se evitar atividades que envolvam apenas cálculos ou a reprodução de algoritmos relacionados ao tratamento de dados de forma estritamente numérica, de tal modo que se conheça a finalidade do uso dos dados específicos e em que contexto foram coletados.

Outro ponto a ser considerado, segundo Hoerl (1997), está relacionado ao uso completo dos processos de pesquisa estatística, visto que, segundo o autor, o entendimento e a apreensão dos conteúdos estatísticos podem ser ampliados. Consoante a essa ideia, Campos, Wodewotzki e Jacobini (2013) explanam acerca da relevância dos dados e da pesquisa realizada serem constantemente questionados pelos estudantes. Dessa forma, percebe-se o pensamento estatístico como uma competência além das habilidades de uso de ferramentas de cálculo inerentes ao contexto estatístico, mas sim, do uso da percepção, da compreensão e da crítica do processo.

Pfannkuch e Wild (2004) propuseram cinco tipos de pensamentos considerados 
fundamentais, sendo eles:

i) Reconhecimento da necessidade de dados: relaciona-se com os fundamentos da investigação estatística, baseado no pressuposto de que muitas situações reais não podem ser julgadas sem uma coleta e uma análise de dados adequadas. A evidência anedótica ou a própria experiência pode não ser confiável, tornandose enganosa para julgamentos e tomada de decisões. Portanto, dados coletados adequadamente são considerados um requisito primordial para a formação de julgamentos confiáveis sobre situações reais.

ii) Transnumeração ${ }^{1}$ : trata-se da mudança de registros de representação, de modo a possibilitar a compreensão do problema. Tal tipo de pensamento ocorre quando (i) são encontradas medidas que caracterizam ou designam qualidades de uma situação real; (ii) são gerados gráficos e tabelas a partir dos dados coletados; e (iii) o significado dos dados e o julgamento sobre eles são comunicados de forma que sejam compreendidos pelos receptores.

iii) Consideração sobre a variação: baseia-se em perceber como as estratégias utilizadas para estudar os dados sofrem influência da variação desses. Inclui-se, aqui, as tomadas de decisão relacionadas a redução da variabilidade como, por exemplo, ignorar ou não outliers, corrigir erros de medidas, entre outros;

iv) Raciocínio com modelos estatísticos: trata-se de um pensamento sobre o comportamento global dos dados. Pode ser acessado por meio de uma análise de regressão, por séries temporais ou por meio de ferramentas mais simples, como gráficos estatísticos ou medidas de tendência central;

v) Integração contextual da Estatística: relaciona-se à análise dos resultados dentro do contexto do problema estudado e a validação destes de acordo com os conhecimentos relacionados ao contexto.

É importante perceber a necessidade de uma mudança de paradigma para que o estudante seja capaz de desenvolver tais pensamentos. Com isso, é necessário um processo de revolução interna com o intuito de renunciar ao olhar determinístico sobre o mundo,

\footnotetext{
${ }^{1}$ Tradução para a Língua Portuguesa comumente utilizada para o termo "transnumeration", criada por Pfannkuch e Wild (2004).
} 
inerente ao ambiente matemático, para adoção de uma visão probabilística, levando em consideração a variabilidade e o processo estatístico envolvido na pesquisa realizada.

Em síntese, entende-se que ao desenvolver o pensamento estatístico busca-se a compreensão dos modelos de problemas e das ferramentas de resolução que cada modelo descreve, tendo como meta reconhecer a aplicabilidade desses modelos nos problemas reais. Para tanto, é necessário que as questões inerentes ao processo de ensino e aprendizagem envolvidas em um trabalho quantitativo superem o estudo de métodos e conceitos estatísticos. Também, essas questões deverão desenvolver-se em um contexto significativo para os estudantes por meio do uso de dados reais coletados pelos próprios estudantes.

\section{METODOLOGIA}

Este artigo é um recorte de uma pesquisa de mestrado que teve cunho exploratório sobre o desenvolvimento de competências estatísticas. A pesquisa foi desenvolvida com base na experiência planejada e executada em uma turma do Terceiro Ano do Terceiro Ciclo (equivalente ao nono ano) do Ensino Fundamental de uma Escola da Rede Municipal de Porto Alegre, localizada no extremo-Norte da cidade. A região a qual a referida escola se encontra é conhecida historicamente por, no final da década de 1980, centenas de homens e mulheres realizarem a ocupação de imóveis, muitos deles inacabados devido à falência do Banco Nacional de Habitação e abandonados pelas construtoras Guerino e Habitasul, pela necessidade de obtenção de moradia para abrigar suas famílias.

A prática ocorreu entre os meses de maio e junho de 2018, totalizando 21 encontros, perfazendo uma carga horária total de 16 horas e 30 minutos. Os encontros realizaram-se ao longo dos períodos destinados a disciplina de Matemática, ministrados por um dos autores do presente artigo.

Enquanto proposta metodológica e de ação docente, optou-se pela adoção da Modelagem Matemática, na perspectiva sócio-crítica (BARBOSA, 2006), a qual coloca o estudante na posição de protagonista no processo investigação, ao passo que o professor atua no papel de mediador do processo. É importante ressaltar que, por estar alinhado com os preceitos da Educação Matemática Crítica (SKOVSMOSE, 2000), tal perspectiva apresenta objetivos pedagógicos relacionados ao desenvolvimento do pensamento crítico 
sobre o papel e a natureza dos modelos matemáticos, além da função da matemática na sociedade. Além disso, relaciona-se com a ideia de formar estudantes autônomos e preparados para desempenhar a cidadania, a partir da reflexão acerca do contexto em que esses sujeitos estão inseridos (KAISER; SRIRAMAN, 2006). Destacamos aqui a experiência de transposição dessa metodologia, ora definida no campo da Educação Matemática, como alternativa para a construção das competências preconizadas pela Educação Estatística.

De modo a proporcionar tal experiência, sob a ótica da Modelagem Matemática na perspectiva sócio-crítica (BARBOSA, 2001), os estudantes foram convidados a explorar a comunidade em que a escola está inserida, realizando uma pesquisa de campo, sendo os protagonistas em todas as etapas propostas (organização da pesquisa, coleta e análise dos dados). Dessa forma, a ação docente se deu ao mediar a construção do conhecimento e ao apresentar e instigar a discussão dos conceitos necessários para cada etapa. O detalhamento da proposta aqui apresentada está descrito em Schwanck (2019).

Para iniciar os trabalhos com os estudantes, durante o primeiro encontro e parte do segundo encontro, realizou-se uma discussão sobre as noções de senso comum e conhecimento científico, de modo a culminar na apresentação da pesquisa estatística enquanto meio para obter-se um conhecimento científico. Em seguida, apresentou-se as etapas do processo de pesquisa estatística a fim de sistematizar a sequência de ações para se obter o resultado esperado ou, quando for o caso, confirmar ou refutar uma hipótese.

Na sequência, entre a segunda parte do segundo encontro e o quarto encontro, realizou-se a construção dos conceitos de variáveis e seus tipos, população e amostra e, paralelamente, definiu-se o tema de pesquisa, as perguntas a serem utilizadas na coleta de dados e a estratégia para a referida coleta. Neste momento, os estudantes escolheram como tema geral a "Caracterização das residências da região" em que a escola se encontra, assim como as variáveis de estudo e que os dados seriam coletados por meio de entrevistas em locais de referência para a comunidade, como a Unidade Básica de Saúde e a praça próxima à Escola.

Com o avanço da prática, durante o quinto encontro e a primeira parte do décimo terceiro encontro, tendo em vista a necessidade de consolidação dos conceitos básicos para a pesquisa estatística e a necessidade de organizar os dados obtidos pelos estudantes, 
desenvolveu-se a construção de tabelas de frequência, abarcando as frequências absoluta e relativa e suas representações gráficas, a partir do uso de recursos computacionais, escolhidos conforme a disponibilidade da escola e/ou acesso dos estudantes. Foi proposta a utilização, como apoio ao processo de organização/tabulação dos dados, de um formulário desenvolvido na ferramenta online Formulários Google $e^{2}$. A partir da exportação do banco de dados completo, fizemos uso do Planilhas Google ${ }^{3}$.

Por fim, para a criação de um relatório com maior rigor estatístico, a partir da segunda parte do décimo terceiro encontro, estendendo-se até o décimo oitavo encontro, foram construídos os conceitos relacionados às medidas de tendência central (média, moda e mediana) e suas interpretações. Oportunamente, o conceito de variabilidade foi introduzido, assim como as discussões acerca dos resultados obtidos pela pesquisa. Como referência para as definições dos conceitos estatísticos, foi utilizado o livro Estatística Básica (MORETTIN; BUSSAB, 2010).

É importante destacar que, na etapa de análise dos dados citada anteriormente, houve a interrupção do atendimento na escola durante quinze dias, devido a um problema elétrico. Este fato pode ser o responsável por uma mudança no comportamento dos estudantes, no que diz respeito à participação na realização da referida etapa e, consequentemente, afetou as discussões e resultados aqui apresentadas.

Tendo em vista o objetivo de identificar elementos potenciais para o desenvolvimento de uma de pesquisa estatística, em comunhão aos preceitos da Modelagem Matemática, no contexto em que uma escola está inserida, esta pesquisa caracteriza-se, portanto, como uma pesquisa qualitativa, que, conforme Biklen e Bogdan (1991), tem como objetivo "[...] melhor compreender o comportamento e experiências humanos".

Neste sentido, os chamados elementos potenciais são diretrizes que emergiram ao longo da experiência vivenciada pelo educador e pelos estudantes. Estes elementos, visualizados como um conjunto de diretrizes, podem orientar outros educadores para a reflexão e elaboração de propostas pedagógicas que objetivem o desenvolvimento das competências estatísticas.

${ }^{2}$ https://www.google.com/intl/pt-BR/forms/about/

3 https:/www.google.com/intl/pt-BR/sheets/about/ 
Ao longo da experiência, foram utilizadas diferentes estratégias de coletas de dados. Entretanto, é importante salientar que, para este estudo, os principais recursos utilizados como fonte de dados são os vídeos feitos durante a execução da experiência. Isso se mostra relevante quando Powell e Silva (2015) nos esclarecem que

A filmagem possibilita a articulação de informações associadas - como áudio e vídeo -, o que viabilizará uma triangulação de dados e, consequentemente, maior confiabilidade na análise (p. 30)

Para tanto, Powell, Franscisco e Maher (2004) nos explicam que, ao utilizar a filmagem enquanto recurso de análise, devemos identificar um evento crítico, que é definido como um acontecimento que

demonstra uma significativa ou constante mudança em relação a uma compreensão prévia, um salto conceitual em relação a uma concepção anterior [...] a relação entre eventos críticos e questões de pesquisa consideradas implica também que os pesquisadores podem identificar como sendo eventos críticos aqueles que incluem instâncias negativas de uma hipótese, instâncias de saltos equivocados e, de alguma forma, significativos para a questão de pesquisa do estudo (pp. 104-105)

A pesquisa aqui proposta não ensejou qualquer tipo de avaliação sobre o resultado dos estudantes de modo a atribuir-se nota ou conceito para fins escolares. Além disso, comprometeu em preservar o anonimato dos participantes, deixando-os livres para ingressarem e, caso fosse de sua vontade, saírem da pesquisa a qualquer momento. Para conhecimento dessas condições, os estudantes e seus responsáveis tiveram acesso ao Termo de Consentimento Livre e Esclarecido e ao Termo de Assentimento, o qual foi assinado por todos os que aceitaram participar da pesquisa. Além disso, a Equipe Diretiva da escola onde foi desenvolvida a pesquisa, composta pela Direção, Supervisão e Orientação Pedagógica, tomou ciência, concordou e acompanhou o projeto desenvolvido em sala de aula pelo professor-pesquisador.

\section{ANÁLISE E DISCUSSÃO DOS DADOS}

Esta seção dedica-se a explicitar alguns eventos críticos (POWELL; FRANSCISCO; MAHER, 2004) relacionados a etapa de análise dos resultados obtidos com a pesquisa realizada na comunidade e, a partir dos resultados, identificar quais elementos podem ser considerados geradores de mudança em relação a compreensão prévia dos sujeitos participantes desta experiência pedagógica. A escolha dos cenários a seguir se 
deu pelo recorte escolhido para o presente artigo, no que diz respeito aos objetivos elencados anteriormente.

\section{Primeiro evento crítico: 14 de junho de $2018,16^{\circ}$ encontro}

No decorrer desse encontro, os estudantes verificaram os resultados da pesquisa relacionados às residências e ao seu tipo de ocupação. Os resultados obtidos foram organizados, conforme a Tabela 1, e analisados.

Tabela 1 - Ocupação das residências.

\begin{tabular}{cc}
\hline Ocupação da residência & Frequência \\
\hline Alugada & $15,52 \%$ \\
Própria & $84,48 \%$ \\
\hline Total geral & $100 \%$ \\
\hline
\end{tabular}

Fonte: resultados da pesquisa dos estudantes.

Ao analisarem a organização dos dados de forma resumida na tabela, os estudantes propuseram a construção de um gráfico de setores para que as proporções se tornassem evidentes a quem fosse visualizar os resultados da pesquisa. Assim, obteve-se como resultado o Gráfico 1.

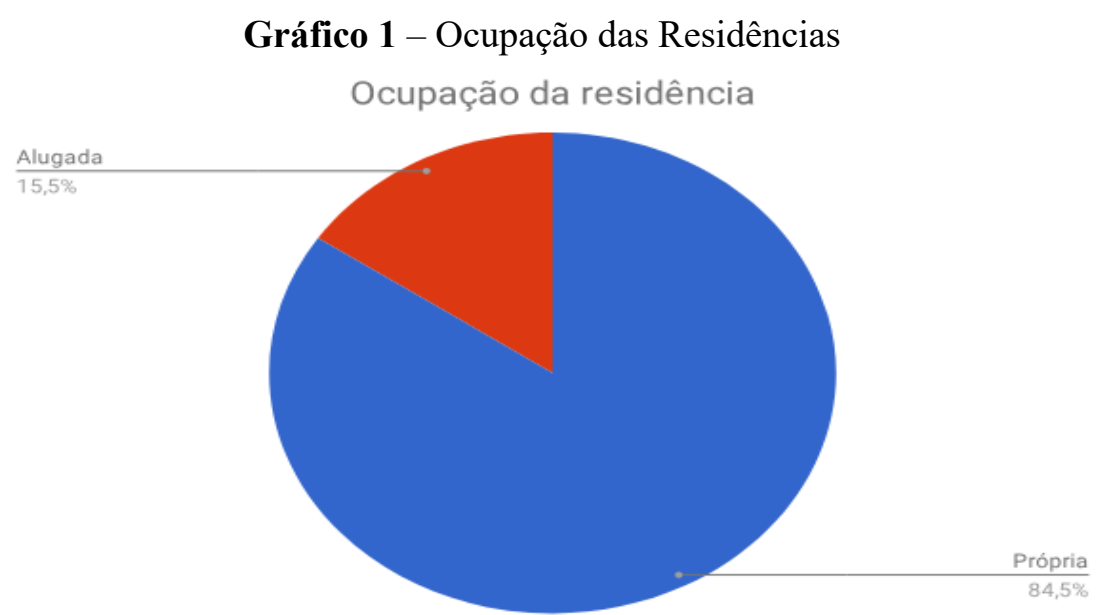

Fonte: Resultados da pesquisa dos estudantes.

Com os resultados observados foram discutidos os aspectos já trazidos como hipóteses pelos estudantes de que muitas das residências da região estudada seriam oriundas de ocupações atualmente legalizadas. Corroborando tal hipótese, a estudante R. 
expõe:

[14/06/2018 10:18 - estudante R.]: É que o que que aconteceu quando o Parque dos Maias foi vendido? A Habitasul tava tirando todo mundo, eles tavam vendendo os apartamentos por um preço ridículo, assim, bem baratinho [...]. Porque o pessoal invadiu e não pagou.

Além disso, os dados também foram responsáveis pela discussão de outra hipótese concebida pelos estudantes, que acreditavam que havia residências oriundas de ocupações recentes na região do Parque dos Maias. Isso fica evidente na transcrição a seguir:

[14/06/2018 12:02 - professor-pesquisador]: Vamos lembrar de uma coisa. Lembram que a gente tinha comentado que aqui, na região do Parque dos Maias, ainda existiam regiões que eram regiões de ocupação?

[14/06/2018 12:22 - estudantes R. e Y.] Sim.

[14/06/2018 12:25 - professor-pesquisador]: O que será que pode ter acontecido para que a gente não tenha nenhuma resposta de...

[14/06/2018 12:36 - estudante Y.]: As pessoas ficarem com vergonha. [14/06/2018 12:25 - professor-pesquisador]: É uma possibilidade. Ou talvez... [14/06/2018 12:36 - estudante R.]: Ou incluíram na própria.

Assim, discute-se em que regiões as supostas áreas ocupadas ficavam e, ao identificarem esses espaços, os estudantes percebem que estão fora dos limites da região do Parque dos Maias. Com isso, conclui-se que não há condições de corroborar a hipótese estabelecida pelos estudantes no início da pesquisa. Dessa forma, percebe-se que há evidências do reflexo da perspectiva sócio-crítica (BARBOSA, 2001) ao longo das discussões ocorridas durante a prática.

Com isso, percebe-se que há uma socialização de um fato desconhecido para muitos dos estudantes presentes. Esse fato contribui tanto com a compreensão do resultado obtido na pesquisa, assim como com o reconhecimento da história da comunidade do Parque dos Maias, possibilitando uma conscientização quanto a importância daquele território para os moradores, principalmente os mais antigos. No que diz respeito às noções de Estatística, é possível identificar o processo de transnumeração (PFANNKUCH; WILD, 2004), uma das formas de pensamento estatístico que diz respeito à mudança de registros para que haja compreensão dos resultados.

Chance (2002) explana que o pensador estatístico é capaz de questionar espontaneamente e investigar os resultados relacionados aos dados de um certo contexto, indo além daquilo que, de fato, trabalha-se nas aulas de Estatística. Com isso, é possível concluir que, dentre as características do pensamento estatístico, encontra-se o desenvolvimento da habilidade de visualizar o processo estatístico de maneira global, 
identificando e analisando as interações existentes no dado contexto e os seus motivos, assim como compreender suas relações e o significado de possíveis variações, extrapolar a interpretação dos dados naquilo que é prescrito nos textos e propor questões e pressuposições não previstas inicialmente. Decorrente disso, podemos sinalizar que há indícios de desenvolvimento do pensamento estatístico sobre a verificação de que não há dados que comprovem a existência das regiões de ocupação, entretanto, há elementos que são indícios para as respostas obtidas.

\section{Segundo evento crítico: 15 de junho de $2018,17^{\circ}$ encontro}

Ao longo desse encontro, os estudantes seguiram as análises relacionadas às variáveis Renda Familiar. Ao visualizarem o banco de dados, surge a seguinte discussão:

[15/06/2018 01:52 - estudante Y.]: Eu acho que as maiores respostas é de mil a dois mil.

[15/06/2018 01:54 - professor-pesquisador]: Como é que a gente vai poder perceber isso?

[15/06/2018 01:57 - estudante Y.]: Fazendo um gráfico.

[15/06/2018 01:59 - professor-pesquisador]: A gente pode fazer um gráfico. A gente pode fazer o que mais?

[15/06/2018 02:02 - estudante R.]: Uma média.

[15/06/2018 02:04 - professor-pesquisador]: Será que a gente consegue fazer uma média aqui?

Ao serem questionados sobre a possibilidade de cálculo da média, houve dúvida por partes dos estudantes, entretanto afirmaram que, por se tratar de dados quantitativos, haveria a possibilidade da realização desse cálculo, mesmo com os dados agrupados. A partir disso, o professor pesquisador explica que é possível, mesmo que em um conjunto de classes numéricas, realizar o cálculo da média a partir da determinação do ponto médio de cada classe, efetuando o somatório do produto desses pontos médios pelas frequências absolutas das classes relacionadas e, por fim, dividindo este somatório pelo somatório das frequências absolutas ${ }^{4}$. Assim, implementou-se na planilha eletrônica essa funcionalidade.

Com isso foi construído o Gráfico 2, assim como foi realizado o cálculo da renda média familiar das residências da região do Parque dos Maias, que correspondeu a R\$ $2.758,62$.

\footnotetext{
${ }^{4}$ Vide https://www.stoodi.com.br/resumos/matematica/medidas-para-dados-agrupados/. Acesso em 12 mai. 2018 .
} 
Gráfico 2 - Renda Familiar

Renda Familiar

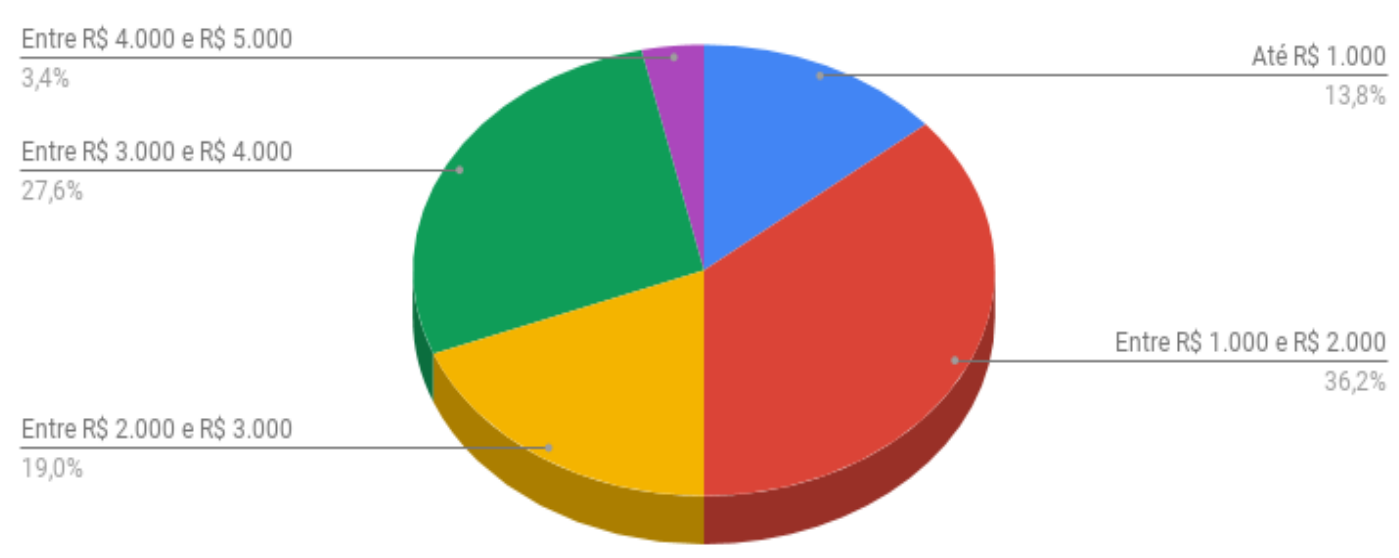

Fonte: Resultados da pesquisa dos estudantes.

Ao serem confrontados com o valor oficial do salário mínimo nacional no período da realização da pesquisa ( $\left.\mathrm{R} \$ 954^{5}\right)$ e os dados da pesquisa que gera o valor do salário mínimo necessário para uma família de quatro pessoas ( $\mathrm{R} \$ 3.804,06$ ), organizado pelo DIEESE $^{6}$, os estudantes propuseram a construção da Tabela 2, a fim de estabelecer relações possíveis entre as informações disponíveis. Com base nos fatos anteriormente citados e levando em conta que a média de moradores por residência era de 3,19 pessoas, chegaram à conclusão que mais da metade das residências pesquisadas vive com uma renda inferior ao salário mínimo necessário, porém, quando levado em consideração o salário mínimo nacional, esse grupo reduz a, no máximo, 13,79\% das famílias, constatando as diferentes interpretações possíveis, à luz de diferentes valores de referência. Tais dados explicitaram conhecimentos já trazidos anteriormente pelos estudantes, como o fato do custo de vida na região, reconhecida por eles como periférica, é inferior às regiões localizadas em direção ao centro da cidade, conforme dados do ObservaPOA ${ }^{7}$, referentes ao ano de 2010.

\footnotetext{
${ }^{5}$ Fonte: https://g1.globo.com/economia/noticia/salario-minimo-em-2018-veja-o-valor.ghtml.

${ }^{6}$ Departamento Intersindical de Estatística e Estudos Socioeconômicos - https://www.dieese.org.br/.

${ }^{7}$ Observatório da Cidade de Porto Alegre - http://www.observapoa.com.br/.
} 
Tabela 2 - Renda familiar.

\begin{tabular}{cc}
\hline Renda familiar & Frequência Relativa \\
\hline Até R\$ 1.000 & $13,79 \%$ \\
Entre R\$ 1.000 e R\$ 2.000 & $36,21 \%$ \\
Entre R\$ 2.000 e R\$ 3.000 & $18,97 \%$ \\
Entre R\$ 3.000 e R\$ 4.000 & $27,59 \%$ \\
Entre R\$ 4.000 e R\$ 5.000 & $3,45 \%$ \\
\hline Total geral & $100,00 \%$ \\
\hline
\end{tabular}

Fonte: Resultados da pesquisa dos estudantes.

Portanto, percebemos o uso e o desenvolvimento de mais uma das competências preconizadas por Gal (2002), o letramento estatístico, ao compreenderem a capacidade de cruzamento e de comparação de informações de diferentes fontes para a construção de um novo conhecimento e, posteriormente, realizarem uma crítica ao contexto dos dados. Além disso, o conhecimento construído pelos estudantes propiciou uma melhor compreensão do contexto relacionado à comunidade em que a escola se insere.

Os eventos críticos aqui descritos indicam que a pesquisa estatística desenvolvida pelos estudantes foi bem sucedida, tanto na produção dos resultados estatísticos bem como na interpretação adequada desses resultados. Pode-se avaliar que isto ocorreu em virtude de o educador ter feito uma mediação adequada ao longo do processo experienciado, ter proporcionado um ambiente propício à autonomia e autoria do estudante, a valorização do trabalho e o desenvolvimento de espaço colaborativo de trabalho, ou seja, os elementos potenciais foram identificados.

\section{CONSIDERAÇÕES FINAIS}

$\mathrm{O}$ estudo aqui apresentado ensejou emergir elementos potenciais para o desenvolvimento de uma proposta de pesquisa estatística, em comunhão aos preceitos da Modelagem Matemática, no contexto em que uma escola está inserida. Ao final dessa jornada, pode-se afirmar que a pesquisa estatística em si se destaca como elemento potencial, tendo em vista a valorização do contexto da escola e de sua comunidade. Além disso, a oportunidade de vivenciar a experiência de uma pesquisa estatística na comunidade por meio da Modelagem Matemática possibilitou a construção de um espaço colaborativo durante a realização do trabalho investigativo. Ademais, os estudantes foram capazes de 
perceber a aplicação dos saberes estatísticos, tornando-os ferramenta para a validação dos conhecimentos gerados pela pesquisa.

Podemos destacar, enquanto elementos potenciais para o desenvolvimento das competências estatísticas em um processo de pesquisa na comunidade, a mediação adequada ao longo do processo experienciado - seguindo os preceitos da perspectiva sóciocrítica -, um ambiente que propicie a autonomia e considere relevante as percepções trazidas pelos estudantes ao analisar as informações por eles construídas, a valorização do trabalho desempenhado pelos estudantes, assim como o desenvolvimento de um espaço colaborativo de trabalho. Para além dos conceitos desenvolvidos, espera-se que os aspectos sociais estejam conectados ao longo da construção do conhecimento. Para tanto, pode-se destacar que elementos demográficos possibilitaram discussões relacionadas às questões de gênero e de renda, temáticas essas que são marcantes na comunidade pesquisada. Além disso, o resgate histórico da organização e formação dessa população emergiu como catalisador para as discussões.

Ao explorar a pesquisa estatística em um ambiente colaborativo, como propõe a perspectiva sócio-crítica de Modelagem Matemática, sujeita-se a experienciar o protagonismo do estudante na construção do seu conhecimento. Esse é o primeiro passo para uma mudança enquanto professor/educador no caminho de uma educação para a autonomia cidadã.

Percebeu-se, ao longo da experiência relatada e por meio do envolvimento dos estudantes, que há indícios de que a estratégia metodológica abordada é capaz de proporcionar motivação para a execução de propostas pedagógicas de natureza prática e autônoma. Parte desse sentimento tem relação com o interesse da temática abordada, entretanto, é percebido que o aceite ao convite à experiência não é garantia da adesão à prática, o que faz com que o papel do professor/educador seja de constante atenção para além do domínio dos conceitos.

Tendo em vista os dados produzidos, identificou-se a mobilização do letramento estatístico e do pensamento estatístico de forma explícita. O domínio da linguagem estatística apresentada tornou-se perceptível na etapa de apresentação, análise e interpretação dos dados, porém restrita às ferramentas utilizadas para execução dessa etapa.

Com as discussões realizadas a partir dos resultados da pesquisa realizada pelos 
estudantes, percebeu-se que eles, de posse dos conhecimentos emergidos e em colaboração com seus pares, puderam transpor o aspecto estatístico para um contexto de crítica social e de desmistificação de preconceitos. Os eventos críticos citados mostram essa mobilização de percepções e a construção de uma crítica social relacionada às percepções prévias, além da possibilidade de ressignificação de conceitos pré-concebidos. Dessa forma, foi possível compreender que o desenvolvimento deste estudo possibilitou aos estudantes refletirem criticamente para responderem seus questionamentos sobre os aspectos socioculturais, competência fundamental para o pleno desenvolvimento da cidadania, demonstrando o sucesso da escolha da perspectiva sócio-crítica de Modelagem Matemática enquanto metodologia de ensino adotada.

Ao revisitar as etapas da pesquisa e enxergar seus resultados, se vê que a exploração da perspectiva sócio-crítica de Modelagem Matemática apresenta-se como um terreno fértil. Inúmeras são as possibilidades vislumbradas como, por exemplo, a adaptação da pesquisa aqui apresentada no contexto do Ensino Médio, ou, ainda, voltar-se a uma das competências estatísticas de forma exclusiva. Consoante aos referenciais preconizados ao longo do trabalho, para além do conteúdo, o uso do conhecimento construído deve impactar na capacidade de refletir acerca do contexto em que o sujeito está inserido, assim como preparar o estudante para usá-lo ao seu favor e da sociedade.

\section{REFERÊNCIAS}

BARBOSA, J. C. Modelagem na Educação Matemática: contribuições para o debate teórico. In: REUNIÃO ANUAL DA ANPED, 24., 2001, Caxambu. Anais... Rio Janeiro: ANPED, 2001. 1 CD-ROM.

BARBOSA, J. C. Mathematical modelling in classroom: a socio-critical and discursive perspective. Zentralblatt für Didaktik der Mathematik, Costa Rica, vol. 38, n. 3, p. 293-301, 2006. Disponível em: https://link.springer.com/article/10.1007/BF02652812. Acesso em: 04 jan. 2019.

BATANERO, C. Didáctica de la Estadística. Granada: Universidad de Granada, 2001. 210 p. Disponível em:

http://aplicaciones2.colombiaaprende.edu.co/ntg/ca/Modulos/estadistica/docs/DidacticaD elaEstadistica.pdf. Acesso em: 12 fev. 2019.

BIKLEN, S. K.; BOGDAN, R. Investigação Qualitativa em Educação: uma introdução à teoria e aos métodos. Porto: Porto Editora, 1991.

BORBA, R. E. S; MONTEIRO, C. E.; GUIMARÃES, G. L.; COUTINHO, C.; KATAOKA, V. I. Educação Estatística no Ensino Básico: Currículo, pesquisa e prática 
em sala de aula. EM TEIA: Revista de Educação Matemática e Tecnológica Iberoamericana, v. 2, n. 2, nov. 2011. Disponível em:

https://periodicos.ufpe.br/revistas/emteia/article/view/2153. Acesso em: 19 nov. 2017.

BRASIL. Ministério da Educação. Secretaria de Educação Fundamental. Base Nacional Curricular Comum: Ensino Fundamental. Brasília: MEC, 2017.

CAMPOS, C. R. A educação estatística: uma investigação acerca dos aspectos relevantes à didática da estatística em cursos de graduação. 2007. 242 p. Tese (doutorado) - UNESP, Rio Claro (SP), 2007. Disponível em:

https://repositorio.unesp.br/bitstream/handle/11449/102161/campos_cr dr_rcla.pdf?sequ ence $=1 \&$ is Allowed $=\mathrm{y}$. Acesso em: 11 set. 2018.

CAMPOS, C. R.; WODEWOTZKI, M. L. L; JACOBINI, O.R. Educação Estatística: teoria e prática em ambientes de modelagem matemática. 2. ed. Belo Horizonte:

Autêntica, 2013.

CHANCE, B. L. Components of statistical thinking and implications for instruction and assessment. In: Journal of Statistics Education, v. 10, n. 3., 2002. Disponível em: http://www.amstat.org/publications/jse/v10n3/chance.html. Acesso em: 25 mar. 2019.

GAL, I. Adults Statistical Literacy: meanings, components, responsibilities.

International Statistical Review, v. 70, n. 1, 2002.

GAL I. Statistical Literacy. In: The Challenge of Developing Statistical Literacy, Reasoning and Thinking. p. 47-78. Dordrecht :Springer, 2004

GARFIELD, J.; GAL, I. Assessment and Statistics Education: Current Challenges and Directions. International Statistical Review, v. 67, n. 1, 1999.

HOERL, R. W. Introductory statistical education: radical redesign is hended, or is it?. In: Newsletter for the section on Statistical Education of the American Statistical Association, 1997. Disponível em: <rendir.vill.edu/ short/StatEd/v3n1/Hoerl.html>. Acesso em: 17 ago. 2018.

KAISER, G.; SRIRAMAN, B. A global survey of international perspectives on modelling in mathematics education. Zentralblatt für Didaktik der Mathematik, Costa Rica, vol. 38, n. 3, p. 302-310, 2006. Disponível em:

http://link.springer.com/article/10.1007/BF02652813. Acesso em: 04 jan. 2017.

MALLOWS, C. The zeroth problem. In: The American Statistician, 52., p. 1-9, 1998.

MOORE, D. S. Foreword. In: BEN-ZVI, D.; GARFIELD, J. (Eds.). The Challenge of

Developing Statistical Literacy, Reasoning and thinking. Dordrecht, The Netherlands:

Kluwer Academic Publishers, 2004, p. ix-X.

MORETTIN, P. A.; BUSSAB, W. O. Estatística Básica. 6. ed. São Paulo: Saraiva, 2010.

PFANNKUCH, M. \& WILD, C. Towards an Understanding of Statistical Thinking. In:

The Challenge of Developing Statistical Literacy, Reasoning and Thinking, p. 17-46. Dordrecht, Holanda: Kluwer Academic Publishers, 2004.

POWELL, A.; FRANCISCO, J.; MAHER, C. Uma abordagem à Análise de Dados de Vídeo para investigar o desenvolvimento de ideias e raciocínios matemáticos de 
estudantes. Tradução de Antônio Olimpio Junior. Boletim de Educação Matemática BOLEMA. Rio Claro, n. 21, 2004. Disponível em:

http://www.periodicos.rc.biblioteca.unesp.br/index.php/bolema/article/view/10538/6944. Acesso em: 19 nov. 2018.

POWELL, A. B.; SILVA, W. Q. da. O Vídeo na Pesquisa Qualitativa em Educação Matemática: Investigando pensamentos de alunos. In: Arthur Powell. (Org.). Métodos de pesquisa em educação matemática usando escrita, vídeo e internet. 1. ed. São Paulo: Mercado de Letras, 2015, v. 1, p. 15-60.

RUMSEY, D. J. Statistical Literacy as a goal for introductory Statistics courses. In: Journal of Statistics Education, v. 10, n. 3., 2002. Disponível em: http://jse.amstat.org/v10n3/rumsey2.html. Acesso em: 25 mar. 2019.

SANTOS, R. M. dos. Estado da arte e história da pesquisa em educação estatística em programas brasileiros de pós-graduação. 2015. 348 p. Tese (doutorado) UNICAMP, Campinas (SP), 2015. Disponível em: http://www.repositorio.unicamp.br/handle/REPOSIP/305010. Acesso em: 11 set. 2018

SCHWANCK, D. I. Pesquisa estatística na comunidade como elemento potencial para o desenvolvimento das competências estatísticas. 2019.79 p. Dissertação (mestrado) - UFRGS (RS), 2019. Disponível em: https://lume.ufrgs.br/handle/10183/201416. Acesso em: 02 nov. 2020.

SKOVSMOSE, O. Cenários para Investigação.Tradução de Jonei Cerqueira Barbosa Boletim de Educação Matemática - BOLEMA. Rio Claro, v. 13, n. 14, p. 66-91, 2000. Disponível em:

http://www.periodicos.rc.biblioteca.unesp.br/index.php/bolema/article/view/10635/7022. Acesso em: 04 jan. 2017.

SOARES, M. Letramento. In: CEALE. Glossário Ceale: Termos de Alfabetização, Leitura e Escrita para educadores. Belo Horizonte: UFMG/Faculdade de Educação, 2014. ISBN 978-85-8007-079-8. Disponível em:

http://www.ceale.fae.ufmg.br/app/webroot/glossarioceale/. Acesso em: 14 jul. 2019.

SNEE, R. D. Discussion: development and use of statistical thinking: a new era'. In: Internacional Statistical Review, 67., p. 255-258, 1999. 